\title{
USING THE ROLE PLAY METHOD IN MILITARY PEDAGOGY
}

\author{
Ștefania BUMBUC \\ “Nicolae Bălcescu” Land Forces Academy, Sibiu, Romania \\ stefanabumbuc@gmail.com
}

\begin{abstract}
This paper aims to identify and discuss relevant issues, in terms of military pedagogy, regarding the using of role play in the training of future officers, given the characteristics of the military organization and the psycho-behavioral traits required of commanding officers. A secondary analysis of quantitative and qualitative data (collected through an opinion questionnaire) was conducted. The results show that role play is perceived as an effective method of training, especially for the psycho-behavioral and attitudinal component, and less for the intellectual component of personality. The data show that, although role play is a collective method, which can only take place with the participation of the military team, the process of developing leadership skills is an individual one. Every student, whether actor or observer during the role play, evolves on their own, regardless of their relationship with colleagues or their position in the military team. The timely and proper intervention of instructor-facilitator in the role play could increase the success rate of this pedagogical method.
\end{abstract}

KEYWORDS: role play, military pedagogy, military leadership

\section{Introduction}

In the process of designing training activities, it is important for trainers to consider a number of factors on which depends the success of learning, as it is known that people learn better if they want and like it, if they need that content, if they work on something practical, if they have enough time to process the content and if they receive feedback. Therefore, teachers should design and carry out as many activities as possible that actively involve students, instead of delivering lectures in which students have a passive role. Among the teaching methods used, in general, in military training activities, an increasingly important place is occupied by simulation. Simulation is based on the artificial imitation and production of systems and phenomena or on fictitious actions, but later translatable into real actions, in order to thoroughly acquire knowledge and the correct formation of skills. It is found in military education under two variants: role play and learning on a simulator. Role play seems to be an educational tool liked by both students and trainers who use it. Properly organized and conducted, roleplaying becomes an activating teaching strategy that can incorporate positive elements related to the pleasure of learning and assimilating useful content.

Throughout the three years of study, in the process of initial training of future officers, military academies use two specific forms of role-playing during formal, non-formal and informal activities carried out by military students: (1) commanding (for a short time, around a week) the platoon to which they belong and (2) the assignment, on meritocracy criteria, of the position of the student with the

DOI: $10.2478 /$ raft-2020-0038

(C) 2017. This work is licensed under the Creative Commons Attribution-NonCommercial-NoDerivs 3.0 License. 
highest military rank, to command a platoon of younger colleagues (for an entire year). This student with the highest rank must be for his platoon a commander, an instructor, a good advisor, but also a reliable colleague. From the military pedagogy point of view, this position is in fact a role assigned in the context of a complex role-playing, which gives those students the opportunity to influence the evolution of the subunit they command through the power of personal example. It is also an exercise that simulates almost all the activities which the future officers will carry out after graduating.

\section{The Role Play in the Literature}

The game is defined and analyzed in the literature from multiple perspectives, both as a mental activity, as a teaching method, and at the level of social interaction. The game is a psychic activity specific to childhood, but is present at all psychological ages, as preteen, teen and even adult capitalize it, in combination with the functions of other activities that are prevalent (learning, work or creation) and with some artistic, sports or technology fields.

Over time, multiple theories have been enunciated to explain the origins and forms of manifestation of games, as follows: forms of releasing the excess energy, manifestation of atavisms (hunting instinct, war), exercises to adapt to different situations, forms of recreation and energy supply, ways of obtaining states of satisfaction with the help of imagination that allows modeling reality according to their own desires, expansion of the self in future personal and professional life, forms of expression of fantasy and natural creativity of people.

Adult play often appears as an alternative to work, it is expressed in extremely diverse forms, conditioned by the social environment, traditions, community, age, territorial area. Pedagogical games are developed by educators for students of any age, aiming at the formation of practical skills, cognitive, social and relationship skills. The pedagogical theory of the game highlights a series of characteristic notes of this activity, thus (Doron \& Parot, 1999):

- The game is treated as a formative situation, based on relationships between several actors/players or teams that face respecting certain rules;

-Each player/team has a potential for evolution and training, which is capitalized in the context of existing rules, depending on partners and opponents;

- The collective game offers significant pedagogical resources, which bring it closer to the functioning structure of education conceived as an interaction of roles;

- The existing interactions in the collective game are explained at the level of social interaction.

In postmodern pedagogy, play is "that form of human activity in which social relations between people are re-created in a specific way, different from the utilitarian conditions of real work" (Elkonin, 1980).

Game theory is currently an area of science that studies play outside the realm of childhood activities and attempts to explain human interaction seen as a game, in many situations involving negotiations, in business or other contexts. Thus, the term game is used to refer to an interaction between different agents, governed by a set of specific rules that determine the possible moves of each participant and the winnings for each combination of moves. The findings of these studies help people understand that the outcome of their actions depends not only on the actions themselves, but also on the actions of other participants in that interaction. The study of human interactions as a game starts from the assumptions that players behave rationally, everyone knows that others are rational and all players know the rules of the game. The validity of these hypotheses obviously conditions the validity and applicability of the legitimacies identified by studying the game of human interactions. 
Role play is the most important category of simulation games (Bocos, 2017), which proposes scenarios inspired by community and professional life, with the aim of taking over the proposed roles by participants and engaging the personality in their fulfillment as a social actor and role model. The content of a role play is built pedagogically according to the relationships between people - recreated in school made in the process of operating with objects and tools similar to those in adult professional life. The essential social relationship, received and formally capitalized during the role play, is not "person-object", but "person-person".

\section{Research Methodology}

\subsection{Aim}

The aim is to identify and discuss some relevant aspects from the point of view of military pedagogy, regarding the application of the role play method in the training of future officers, considering the characteristics of the military organization and psycho-behavioral traits of commanding officers, as a distinct socio-professional group.

\subsection{Pedagogical Considerations about Playing the Role of Military Commander}

A role play game generally has three types of participants: actors, observers and facilitator (trainer/teacher/instructor). The role play method go through three methodological phases, as specified by the Center for Enhance Teaching and Learning: (a) the introductory phase, in which the scenario is presented, the roles are assigned, the requirements and the rules are clarified; (b) the game phase, in which the actors begin to play their roles and the facilitator maintains the atmosphere, ensures that things start well, provides guidance, descriptions, comments and encourages, until the actors manage to keep things moving without any an intervention.
At this point the facilitator withdraws, assists, and finally formulates a conclusion, if it does not appear naturally from the interaction; (c) the debriefing phase, in which the actors who finished their roles share their experience to the team, and the discussion is facilitated by the instructor, who highlights the main points that have been reached. All actors should describe the experience, then receive feedback from fellow observers and the instructor. If the role play involves heated interactions, debriefing must reconcile, alleviate any strong feelings or conflicts that have emerged and that might otherwise persist as a result of the activity.

Given the need for the initial professional training of future commanding officers, by playing the role of platoon commander throughout the period of schooling in the military academy, students have the opportunity to develop a range of skills, so:

-Communication. Military leaders have the opportunity to exercise in different contexts the ability to explain clearly and succinctly to subordinates everything from the organization's objectives, the requirements of a mission, to the details of specific work tasks. "Many components are important for effective communication, including active listening, body language reading and written communication" (Cserti, 2018).

-Motivation. Military leaders try to inspire their subordinates, for example by recognizing their efforts and achievements or by giving new responsibilities to people, to continue their work within the organization. The skills to motivate people can be tried, practiced, perfected in different situations created by trainers, by playing the role of platoon commander.

-Delegation. Leaders can do this by identifying the skills that people have and, in doing so, assigning appropriate tasks to each subordinate based on their abilities. 
-Positive attitude. Being positive helps to develop a happy and healthy professional environment, even when the job is demanding or stressful.

- Trust. By demonstrating the integrity of the leader, the fact that he is a trustworthy person, the subordinates will feel at ease and get closer to the leader, they will share what concerns them.

-Creativity. In order to become good leaders, in the role played, future officers have the opportunity to try new solutions or to approach problems in a non-traditional way.

-Responsibility. Playing the role of leader, the military student will be in a position to accept mistakes or failures, of himself and his subordinates, but also to look for solutions to improve a situation. This ability also includes being a thoughtful person and open to feedback.

-Commitment. Students must strive to complete everything they have undertaken to do when they have taken over the role of platoon commander. This involves keeping promises.

-Flexibility. Future leaders will learn to accept unexpected changes, solve problems promptly, and be open to suggestions and feedback.

The role play method has numerous pedagogical advantages, presented in the conclusions of specialized research, as well (Shaw, 2010):

- provides concrete examples for abstract concepts, facilitates development by practicing analytical skills, forms procedural experience and decision-making skills by applying learned concepts in real situations. These can result in deeper learning and appreciation of different perspectives on a topic;

-often results in changes of perspective, increased empathy for others, broader perspectives on the challenges others face, and increased professional and civic involvement;
- tends to increase students' motivation and interest, as evidenced by the increase in student participation and satisfaction in roleplaying subjects, completion of assigned readings and increasing the amount of time spent working independently outside of class hours;

-there is a greater and longer retention of the learned materials;

- often results a better teacher-student relationship and a more relaxed training environment, in which the natural exchange of ideas can take place. Students tend to see the teacher in a more positive light;

- often results in a better understanding of the complexity of situations. They provide openness to a large volume of analysis and structured discussions on the subject;

- enables each member of the student body to implement and improve their social skills to comply with rules and regulations, to show resilience, patience, team spirit and cooperation, as well as to develop intellectual skills of observation, communication, application, appreciation, prediction, deduction, etc. in a risk-free environment. Students are also gradually trained to overcome the shyness and hesitation inherent in inexperience.

-encourages young people to empathize, perceive and become aware of the position, actions and feelings of others, to look beyond assumptions and expectations.

- there are also benefits for teachers/ trainers/instructors, such as keeping content fresh and interesting in the courses they have been teaching repeatedly for a long time; obtaining authentic feedback on what students assimilate well and what is not mastered at the desired level; last but not least, it helps to promote the image of teachers in educational institutions.

The scenarios chosen by educators for role-playing can be authentic (real events that have taken place, for which the solutions are grounded in reality, not fictitious, idealized or simplified) or 
realistic (hypothetical situations, which can combine aspects of several real-world events, but often contain ideal or simplified elements, which exist differently in the real world, and some complications are missing). In the first case, students can later apply what they have learned as such, without adjustments, and in the second case, depending on the degree of fidelity of the scenario to reality, it is necessary a further adjustment by students of what they have learned, in order to it fits the complex phenomena of the real world. Simplified, low-fidelity and well-structured scenarios are best for beginners in a field, lacking the many details that people have to face in the real world. As learners gain experience and deepen their knowledge, the level of complexity and correspondence with realworld situations can be increased, until they can solve high-fidelity scenarios, problems, and unstructured situations.

\subsection{Research Data}

The research method used is the secondary analysis of quantitative and qualitative data. The starting point is the data collected in May 2020 by a graduate of the academy, through an opinion questionnaire applied to a representative sample of military students (157 subjects), future commanding officers. The primary analysis of a part of the collected data was performed and presented by the respective student during the graduation thesis. The research sample is representative for the military academy, in terms of the distribution of subjects by years of study and by sex.

\section{Discussing the Findings}

A first result that caught our attention and that we will analyze further is the fact that, following the role-playing in which they participated, military students consider the roles of actor (commander of the platoon of colleagues) and participantobserver (member of the platoon commanded by a colleague) are almost as effective for learning the profession of officer. To the questions To what extent do you think that fulfilling the role of platoon commander in front of colleagues is a good way to learn the profession of officer? and To what extent do you think that observing how a colleague plays the role of platoon commander is a good way to learn the profession of officer? the positive answers (very large and large extent) were chosen by $87.9 \%$ and $91.7 \%$ of the subjects. The finding that the role of observer is perceived by students as more suitable for acquiring the skills to command the platoon is somewhat surprising, given that people learn more easily and remember better what they perform, than what they see and hear. As it is an opinion questionnaire, it may be just a perception, it does not correspond to reality and it does not reflect the real level of students' professional acquisitions. Regardless of the situation, this perception should be exploited from a pedagogical point of view by facilitators of role-playing. One suggestion would be to intensify (in terms of frequency and depth) the feedback given to the actor in the role of platoon commander by fellow observers. Careful conduct of feedback sessions can have equally beneficial effects for the actor and the observer, especially at the cognitive level (by enhancing specialist information and understanding). On the other hand, the level of skills (professional behaviors in the field of military leadership) and affectiveattitudinal experiences (Maier, 2002) will certainly not be the same for actors and observers in the role play, the practical action being in this case irreplaceable.

This last statement is also supported by the answers of the subjects regarding the categories of acquisition through the participation in role-playing: $70 \%$ stated that they acquired new knowledge, $80 \%$ considered that they acquired skills. However, if we analyze the answers to the open question on exemplifying some of the 
knowledge gained through role play, we find that respondents often referred to procedural knowledge, which can be easily included in the field of skills: ways of relating to subordinates, respect for military ranks, ways of communication with superiors and subordinates, the division of tasks, the transmission of an order from a superior to subordinates etc. Therefore, the role play was also confirmed by military students as a teaching method designed especially for the training of professional skills.

Following the participation in roleplaying, the subjects realized that they lack ( $12 \%$ to a very large extent and $35.9 \%$ to a large extent) certain personal skills and qualities necessary for a military leader. The following categories of difficulties encountered were most frequently mentioned: the difficulty of assuming responsibilities and making decisions for others, the difficulty of managing the dynamics of interpersonal relationships and collective behavior, and the lack of skills of time management. Platoons are generally characterized by a high level of cohesion, giving military students a strong sense of protection and psychological comfort. Related to this, it was noticed a high discomfort of majority of military students who are individually exposed to the first attempts to command the platoon of colleagues.

No significant relation could be identified between the level of discomfort reported by students playing the role of platoon commander and their position in the group's sociogram. In fact, $45 \%$ of the subjects stated (to a very large and large extent) that during and after the role-playing, conflicts occur within the platoon, both vertically (between actorobservers) and horizontally (between observers). One conclusion that can be formulated is that the support of colleagues is not a determining factor in training for the officer profession. The evolution of each to become a good officer is an individual path, based especially on personal qualities (intellectual and personality) and own effort. Observing the performance of colleagues who play the role of platoon commanders has more important effects as a term of comparison for their own performance in that role and less in terms of improving leadership behavior following the feedback from the team. This finding is useful when facilitators plan feedback sessions and debriefings at the end of role-plays, as it is better to give enough time and clearly ask participants to verbalize personal experiences and identify on its own the aspects that deserve to be repeated and those that need to be changed or improved later, in a similar situation.

In addition to the above, we bring the declaration by $52 \%$ of the subjects of the need for help, support, advice from the facilitator of the role play. The fact that the number of subjects who needed an instructor and those who preferred to fend for themselves is approximately equal is an additional argument to support the opportunity for personal development trainings and coaching sessions for the development of military leadership. Role play facilitator intervention should be reconsidered, as subjects stated that they were provided with adequate support to a small extent (29\% of subjects) and to a very small extent (12\% of subjects). Such a failure rate of facilitators, given that they get involved, participate, intervene in the role play, indicates the need to shift the focus from correcting the actor's behavior to the analysis of views, perceptions, solutions proposed by all participants, whether they are actors (platoon commanders) or observers (platoon members). Discussions between facilitators to improve their performance become a necessity to increase the success rate in the application of the role play method. 


\section{Conclusions}

The problem that teachers face is not to engage students in the role play, but rather to establish, facilitate and subsequently evaluate the results to be achieved, respectively the educational objectives that can be achieved through the role play. The effects of role play are, firstly, the acquisition of skills (development of behavioral skills), secondly the improvement of the level of understanding of knowledge (input of information and intellectual understanding), and thirdly the enrichment the affectiveattitudinal experience of the students (awareness of some aspects of the personality and their emotional enrichment).

Several important issues need to be considered by the trainers so that roleplaying games can achieve their goal of professionally preparing future army leaders as well as possible. The officerstrainers' control over the students' role play is essential. Role-playing games often lead a life of their own, sometimes directing them in other directions than expected. The officers-trainers need to anticipate a number of possible ways to deviate from the proposed path and have prepared intervention strategies. At the beginning, the trainer can also play a minor role in the scenario proposed to the students, which will give him access within the group of students and thus be able to exercise a certain control if necessary. Once the platoon has already been involved in a few role-playing games, getting out of the way becomes less likely, and the officer-trainer can gradually reduce his control. There is also the possibility that military students coming from different schools (civilian or military) may respond in unforeseen ways to role-playing games. Advice can be sought from students in various backgrounds, in private, in advance, on such issues. Perhaps some of these students can become more actively involved as facilitators or observers.
The officer-trainer must assist the student-actors in deciding the appropriate way to play their assigned role. Also, some students need time to take on the command role. They need to learn from the trainer that there is no one right way to play a role. The beginnings of playing a role can be slow, there can be blockages in action and moments of discomfort.

Another important methodological aspect to mention is the need to organize for students who play command roles some opportunities for reflection. Reflection and discussion are the main ways of learning from role-playing games. Actors should reflect on what they thought, felt, perceived, acted on and learned from the role they played. Trainers need to examine key role-playing events and discuss what would make them different and why. This also involves reflections of observers, of platoon colleagues who were led for a time by the student who plays the role of commander. It is important for trainers to facilitate discussions without imposing their opinions, but also not to seem a neutral background. If the discussion is slow and no significant ideas appear, it is good for trainers to be prepared to start discussions with some of their own appreciations, to provide provocative feedback to encourage comments and constructive interventions.

Another aspect to be aware of is the emergence of controversies, even conflicts between participants. Trainers need to warn actors and observers that they need to prepare for situations that may provoke or upset them, and they need to stay calm and think before acting or reacting. Learning objectives must be reiterated and it must be explained that this method of practical training is worth using, as it brings military students closer to the officer profession and helps them feel, not just think like a leader, which makes learning be more memorable and more accessible. The limits of the role of commander that students play one by one in front of their colleagues will be clearly established. 
In future research, possibly by organizing pedagogical experiments, certain thresholds, certain levels of competence that must be reached progressively or certain landmarks through which the symbolic path of training the leadership skills of military students must pass can be identified, so that attention and the effort of the participants and the facilitator to intensify in those key moments, generating a higher success of role plays.

\section{REFERENCES}

Bocoș, M. (2017). Dicționar praxiologic de pedagogie. Pitești: Paralela 45.

Centre for Enhanced Teaching and Learning, University of New Brunswick. (n.d.). Creating Effective Scenarios, Case Studies, and Role Plays, available at: https://www.unb.ca/ fredericton/cetl/tls/resources/teaching tips/tt instructional_methods/effective scenarios.html, accessed on 10 September 2020.

Cserti, R. (2018). 12 Effective Leadership Activities and Games, available at: https://www.sessionlab.com/blog/leadership-activities /, accessed on 15 September 2020.

Doron, R., \& Parot, F. (1999). Dicționar de psihologie. Bucharest: Humanitas.

Elkonin, D. B. (1980). Psihologia jocului. Bucharest: Editura Didactică.

Maier, H. W. (2002). Role playing: Structures and educational objectives. CYC-Online, Vol. 36, available at: https://www.cyc-net.org/cyc-online/cycol-0102-roleplay.html, accessed on 10 September 2020.

Roman, M. (n.d.). Jocuri şi negocieri. Bucharest: Academia de Studii Economice, available at: http://www.asecib.ase.ro/Roman/MR.html, accessed on 16 September 2020 .

Shaw, C. M. (2010). Designing and Using Simulations and Role-Play Exercises. The International Studies Encyclopedia, eISBN: 9781444336597. 